Arab Univ. J. Agric. Sci., Ain Shams Univ., Cairo, 13(3), 997 - 1004, 2005

\title{
RESIDUAL BEHAVIOUR OF FLUSILAZOLE AND TRIFLUMIZOLE FUNGICIDES ON AND IN APPLE FRUITS UNDER FIELD CONDITIONS
}

[68]

\author{
Nevein S. Ahmed ${ }^{1}$
}

\begin{abstract}
Flusilazole and triflumizole residues in apple fruits were chemically determined at different periods after spraying of these fungicides under field conditions. The obtained results indicated that, seven days after flusilazole application, unwashed apple fruits were found contained higher residues $(0.322 \mathrm{ppm})$ than the allowed tolerance level $(0.2 \mathrm{ppm})$, while washed and peeled fruits were contained lower residues ( 0.149 and $0.087 \mathrm{ppm}$, respectively) after the same period from experiment. These residues were rapidly decreased by elapse of time, so unwashed, washed and peeled apple fruits were contained levels below the allowed MRL i.e. 0.092, 0.008 and $<0 \mathrm{ppm}$, respectively after fourteen days of flusilazole application Accordingly, unwashed apple fruits could be marketed safely 14 days after flusilazole application, while washed and peeled fruits could be used safely after seven days. In the case of triflumizole, unwashed apple fruits were contained $2.030 \mathrm{ppm}$ after five days of application. Such residue is higher than the tolerance value $(2.0 \mathrm{ppm})$, while washed and peeled fruits were contained residues below the tolerance permissive values i.e. 1.010 and $1.970 \mathrm{ppm}$ after three and one days of application, respectively. These values were rapidly decreased by time prolongation, so, unwashed, washed, and peeled apple fruits were contained residues below the allowed tolerance of 1.280, 0.490 and $0.160 \mathrm{ppm}$ at seven days after triflumizole application, respectively. Accordingly, unwashed apple fruits could be marketed safely seven days after triflumizole application, while washed and peeled fruits could used safely three and one days after application, respectively.
\end{abstract}

Key words: Fungicides, Flusilazole, Triflumizole, Residues, Apple fruits, Washed and peeled process

1- Central Agricultural Pesticides Laboratory, Agricultural Research Center, Dokki, Cairo, Egypt

(Received April 20, 2005)

(Accepted May 23, 2005) 
Arab Univ. J. Agric. Sci., Ain Shams Univ., Cairo, 13(3), 997 - 1004, 2005

\section{INTRODUCTION}

Apple plant (apple orchard) has been planted in large areas in Egypt; therefore, the consumption of these fruits is progressively increased, On the other hand, there is lack of information on the residues of pesticides used in protection apple fruits from pests invasion which caused serious damages. Flusilazole fungicide is effective and recommended against many plant pathogens belongs to ascomycetes, basidiomycetes and deuteromycetes that make damage to many crops such as apples peaches, cereals, grapes and sugar beet while triflumizole fungicide is used for controlling Gymnosporangium and Venturia spp. infesting pome fruit, against powdery Erysiphaceae in fruits and vegetables (Tomlin, 2000).

The performance behaviour of some common fungicides, which are used for controlling target fungi, has been studied by many researchers such as Dzhuvinov and Kutinkova (2003); Podgornaya (2003); Ahmed and Mir (2002); Masng and Bielenin (2002); Reuveni et al (2000); Feng et al (2000) and Mayer \& Lunden (1986).

In Egypt, flusilazole and triflumizole which have protective and curative action were recommended under the trade names of punch $40 \% \mathrm{EC}$ and trifmine $15 \%$ EC, respectively for controlling powdery mildew in apple fields (Pest Control Programme of Egypt 2001 and 2005).

Several attempts have been studied the determination of some fungicide residues in apple fruits and removal those residues from contaminated agricultural products i.e. Hwang et al (2002); Dantas et al (2000); Ong et al (1996) and Sato \& Maki (1989).

The aim of this work was to determine flusilazole and triflumilazole residues in unwashed, washed, and peeled apple fruits and calculated their half-life values.

\section{MATERIAL AND METHODS}

\section{1- Experimental design and treatments}

The experiment was carried out at Kafr Shoker, Kalubia governorate, for determination the residues of flusilazole and triflumizole fungicides in unwashed, washed, and peeled apple fruits under field conditions at different periods after the application upon apple plants. The experimental area was 168.62 square meters ( $1 / 24$ fed.). The tested fungicides were applied on May $21^{\text {st }}, 2004$. These fungicides were used as water emulsion using a knapsack hand sprayer fitted with one nozzle boom. Complete coverage of the treated plants was attained. The untreated control plots were left unsprayed. Also, care was taken to avoid any drift among the treated plots. Three replicates were taken for each treatment. Thus, at the required time, three fruit samples of $1 / 2 \mathrm{~kg}$. each were collected at random. The representative sample was divided into three sub samples, the first

1- Central Agricultural Pesticides Laboratory, Agricultural Research Center, Dokki, Cairo, Egypt 
999

Flusilazole and triflumizole residues in apple fruit

was left unwashed, the second was washed for 3 minutes in running tap water followed by drying, and the third was washed in running tap water and dried then peeled.

Samples were taken; one hour after application (initial), 1, 3, 5, 7, 14, and 2ldays. Punch $40 \%$ EC was used at the rate of $3 \mathrm{~cm}^{3} 100 \mathrm{~L}$ water, while triflumizole $15 \%$ EC was used at the rate of $17.5 \mathrm{~cm}^{3} / 100 \mathrm{~L}$ water.

\section{2-Residue determination}

\section{A) Extraction and clean-up of tested fungicides}

Flusilazole residues were extracted and cleaned-up from apple fruits according to the method of Dupont de Nemours Co. (1989) and Nasr et al (2003), while triflumizole residues were extracted and cleaned up from apple fruits according to the method of Nippon Soda Co., (1984) and Ueno et al (2002).

\section{B) Determination of fungicide residues}

Flusilazole and triflumizole residues were determined by Agilent 1100 serious HPLC fitted with quarterly pump., G131 $1 \mathrm{~A}, \mathrm{UV}$ detector, and stainless steel column (2.6/250mm.) packed with $\mathrm{Cl} 8$ under the following conditions:

Wave length $254 \mathrm{~nm}$., flow rate $\mathrm{lml} / \mathrm{min}$., and mobile phase $80 / 20$ methanol/acetonitrile for flusilazole while they were $230 \mathrm{~nm}$., $1.5 \mathrm{ml} / \mathrm{min}$., and $60 / 40$, respectively for triflumizole. At these conditions the retention times of flusilazole and triflumizole were 3.03 and $3.50 \mathrm{~mm}$., respectively. Recovery studies were done by added known amounts of flusilazole and triflumizole to the untreated apple fruits samples.
Extraction, clean up and fungicides determination were carried out as mentioned above. The average rates of recovery were $92.58 \%$ and $93.75 \%$ for flusilazole and triflumizole, respectively.

\section{C) Kinetic study}

The rate of degradation $(\mathrm{k})$ of the tested fungicides and their half-life period $\left(t_{0.5}\right)$ for the two fungicides on apple fruits were calculated according to the equation:

$t_{0.5}=\ln 2 / k=0.6932 / k$ (Moye et al 1987).

\section{RESULTS AND DISCUSSION}

Data summarized in Tables (1 and 2) represented the amount of flusilazole and triflumizole residues in unwashed, washed, and peeled apple fruits collected from the experiments at different intervals after fungicides spraying, respectively. The obtained results indicated that the initial total deposits of flusilazole found in unwashed, washed, and peeled apple fruits as determined one hour after application were 1.39, 1.17 and 0.84 ppm while they were $5.32,3.41$, and $2.01 \mathrm{ppm}$, respectively for triflumizole. This indicates that the amount of the initial deposits of the two tested fungicides depends mostly upon the rates of their application. The amounts of flusilazole residues in unwashed, washed, and peeled fruits were progressively decreased with elapse of time from spraying to reach undetectable amounts, 21 days of application while they were $0.026 \mathrm{ppm}$ in unwashed fruits and undetectable amounts for triflumizole in washed and peeled fruits.

Flusilazole rates of degradation (k) in unwashed, washed, and peeled apple 


\section{Nevein Ahmed}

fruits were $0.3795,0.5832$, and 0.4799

days, respectively. The corresponding $\mathrm{t}_{0.5}$ values reached $1.8265,1.1885$, and

1.4443 days with the same treatments, respectively. For triflumizole, the respective $(\mathrm{k})$ values were 0.5283 , 0.7080 , and 0.6079 days; the $t_{0.5}$ values reached $1.3120,0.9790$, and 1.142 days in unwashed, washed and peeled fruits.

Such finding indicates that triflumizole was degraded faster than flusilazole when applied on to apple plants. 
Arab Univ. J. Agric. Sci., Ain Shams Univ., Cairo, 13(3), 997 - 1004, 2005

Table 1. Flusilazole residues in unwashed, washed, and peeled apple fruits under field conditions (ppm) at different time intervals

\begin{tabular}{|c|c|c|c|c|c|c|}
\hline \multirow{2}{*}{$\begin{array}{l}\text { Time intervals } \\
\text { in days }\end{array}$} & \multicolumn{2}{|c|}{ Unwashed } & \multicolumn{2}{|c|}{ Washed } & \multicolumn{2}{|c|}{ Peeled } \\
\hline & $\begin{array}{c}\text { Residue } \\
\text { (ppm) }\end{array}$ & $\begin{array}{c}\% \\
\text { loss }\end{array}$ & $\begin{array}{l}\text { Residue } \\
\text { (ppm) }\end{array}$ & $\begin{array}{l}\% \text { loss by } \\
\text { washing }\end{array}$ & $\begin{array}{l}\text { Residue } \\
\text { (ppm) }\end{array}$ & $\begin{array}{c}\% \text { loss by } \\
\text { peeling }\end{array}$ \\
\hline Initial $^{(1)}$ & 1.390 & 0.00 & 1.170 & 15.83 & 0.840 & 39.57 \\
\hline 1 & 1.180 & 15.11 & 0.855 & 27.54 & 0.660 & 44.07 \\
\hline 3 & 0.921 & 33.74 & 0.712 & 22.69 & 0.573 & 37.79 \\
\hline 5 & 0.762 & 45.18 & 0.590 & 22.57 & 0.415 & 45.54 \\
\hline 7 & 0.322 & 76.83 & 0.149 & 53.73 & 0.087 & 72.98 \\
\hline 14 & 0.092 & 93.38 & 0.008 & 91.30 & UND & 100.00 \\
\hline 21 & UND & 100.00 & UND & - & UND & - \\
\hline Slope & \multicolumn{2}{|c|}{0.1648} & \multicolumn{2}{|c|}{0.2533} & \multicolumn{2}{|c|}{0.2084} \\
\hline k math. (days) & \multicolumn{2}{|c|}{0.3795} & \multicolumn{2}{|c|}{0.5832} & \multicolumn{2}{|c|}{0.4799} \\
\hline $\mathrm{t}_{0.5}$ (days) & \multicolumn{2}{|c|}{1.8265} & \multicolumn{2}{|c|}{1.1885} & \multicolumn{2}{|c|}{1.4443} \\
\hline
\end{tabular}

Initial $^{(1)}=$ one hour after application

$\mathrm{k}$ value $=$ rate of degradation

$\mathrm{UND}=$ Undetectable

Each value is the mean of three samples.

Maximum Residue Level $($ MRL $)=0.2 \mathrm{ppm}($ CAC/PR (2003)).

Preharvest Interval $(\mathrm{PHI})=14$ days

1- Central Agricultural Pesticides Laboratory, Agricultural Research Center, Dokki, Cairo, Egypt 
6

\section{Nevein Ahmed}

Table 2. Triflumizole residues in unwashed, washed, and peeled apple fruits under field conditions (ppm) at different time intervals

\begin{tabular}{|c|c|c|c|c|c|c|}
\hline \multirow{2}{*}{$\begin{array}{l}\text { Time intervals } \\
\text { in days }\end{array}$} & \multicolumn{2}{|c|}{ Unwashed } & \multicolumn{2}{|c|}{ Washed } & \multicolumn{2}{|c|}{ Peeled } \\
\hline & $\begin{array}{l}\text { Residue } \\
(\mathrm{ppm})\end{array}$ & $\begin{array}{l}\% \\
\text { loss }\end{array}$ & $\begin{array}{l}\text { Residue } \\
\text { (ppm) }\end{array}$ & $\begin{array}{c}\% \text { loss by } \\
\text { washing }\end{array}$ & $\begin{array}{l}\text { Residue } \\
(\mathrm{ppm})\end{array}$ & $\begin{array}{c}\% \text { loss by } \\
\text { peeling }\end{array}$ \\
\hline Initial (1) & 5.320 & 0.00 & 3.410 & 35.90 & 2.010 & 62.22 \\
\hline 1 & 3.690 & 30.64 & 2.480 & 32.79 & 1.970 & 46.61 \\
\hline 3 & 2.950 & 44.55 & 1.010 & 65.76 & 0.690 & 76.61 \\
\hline 5 & 2.030 & 61.84 & 0.880 & 56.65 & 0.410 & 79.80 \\
\hline 7 & 1.280 & 7594 & 0.490 & 61.72 & 0.160 & 87.50 \\
\hline 14 & 0.530 & 90.04 & 0.083 & 84.34 & UND & 100.00 \\
\hline 21 & 0.026 & 99.51 & UND & 100.00 & UND & 100.00 \\
\hline Slope & \multicolumn{2}{|c|}{0.2295} & \multicolumn{2}{|c|}{0.3075} & \multicolumn{2}{|c|}{0.2640} \\
\hline k math. (days) & \multicolumn{2}{|c|}{0.5283} & \multicolumn{2}{|c|}{0.7080} & \multicolumn{2}{|c|}{0.6079} \\
\hline $\mathrm{t}_{0.5}$ (days) & \multicolumn{2}{|c|}{1.3120} & \multicolumn{2}{|c|}{0.9790} & \multicolumn{2}{|c|}{1.1402} \\
\hline
\end{tabular}

Initial $^{(1)}=$ one hour after application

$\mathrm{k}$ value $=$ rate of degradation

$\mathrm{UND}=$ Undetectable

Each value is the mean of three samples.

Maximum Residue Level (MRL)=2ppm (Nippon Soda Co. Ltd,(2004)).

Preharvest Interval $(\mathrm{PHI})=7$ days 
Arab Univ. J. Agric. Sci., Ain Shams Univ., Cairo, 13(3), 997 - 1004, 2005

It is also noticed that, the residue of flusilazole was declined to $0.322 \mathrm{ppm}$ in unwashed fruits, 7 days after application recording $76.83 \%$ of loss. The residues were lowered to 0.590 and $0.415 \mathrm{ppm}$ in washed and peeled fruits 5 days after spraying, showing 22.57 and $45.54 \%$ loss, respectively.

These values were higher than the MRL i.e. $0.2 \mathrm{ppm}$ adopted by $\mathbf{C A C} / \mathbf{P R}$ (2003). Moreover, flusilazole residues were $0.092 \mathrm{ppm}$ in unwashed fruits, 14 days after application recording $93.38 \%$ of loss compared with 0.149 and 0.087 ppm ( $<$ the tolerance level) in washed and peeled fruits 7 days after application, respectively. As a result, unwashed fruits could be marketed with apparently safety for human consumption after 14 days of flusilazole application while washed and peeled fruits could used safely after 7 days of application.

On the other hand, data also indicated that washing process with running tap water and peeling process of the treated fruits proved very efficient in removal of flusilazole residues by 15.83 to $91.30 \%$ and 39.57 to $100 \%$ through the zero time to 14 days, respectively. These results are in agreement with the findings of Hwang et al (2002); Dantas et al (2000)); Ong et al (1996) and Sato \& Maki (1989).

In the case of triflumizole, unwashed, washed, and peeled apple fruits contained 5.320, 3.410, 2.010 ppm, respectively, one hour after application. Such deposits were degraded by time and reached 2.030 ppm in unwashed fruits 5 days after application recording $61.84 \%$ loss and
$2.480 \mathrm{ppm}$ in washed fruits one day after application. These values were higher than the allowable tolerance level (2 ppm) adopted by Nippon Soda Co. Ltd (2004). While in peeled fruits residue reached $1.970 \mathrm{ppm}$ one day after application ( $<$ allowable tolerance level). Moreover, triflumizole residues were declined to $1.280 \mathrm{ppm}$ in unwashed fruits 7 days after treatment recording $75.94 \%$ dissipation and $1.010 \mathrm{ppm}$ in washed fruits 3 days after application, (< allowable tolerance level). As a result, unwashed fruits could be marketed with apparent safety for human consumption after 7 days of triflumizole application. Washed and peeled fruits could used safely after 3 and one days of spraying, respectively.

On the other hand, Data also indicated that washing process with running tap water and peeling process of the contaminated fruits proved very efficient in removal of triflumizole residues by 35.90 to $100 \%$ and 62.22 to $100 \%$ from zero to 21 days, respectively. These results are in agreement with those obtained with Hwang et al (2002); Dantas et al (2000); Ong et aI (1996) and Sato \& Maki (1989).

\section{REFERENCES}
Ahmed, Q.V. and N.A. Mir (2002).
Comparison of different spray schedules for control of Venturia inequalis infection of apple cv. "red delicious" in Kashmir. Applied Biological Research, 4(1-2): 43- 51.

\section{Codex Alimentarius Committee for}

1- Central Agricultural Pesticides Laboratory, Agricultural Research Center, Dokki, Cairo, Egypt 
Pesticides Residues (CAC/PR) (2003). Guide to Codex Recommendations concerning pesticide of residues, Maximum Limits for Pesticide Residues, FAQ/WHO, Part (1): 182.

Dantas, A.C.De.M.; J.E.S. Pereira;

G.R.De.L. Fortes and G.R. Fortes (2000). Decontamination and the effect of benomyl fungicide on the multiapplication of the apple rootstock. Agropecuaria China Temperado, 3(2): 245-252.

Dupont de Numours Co. (1989).

Residue procedures for the organosihicone triazole fungicide.

Dupont de Nemours Company-USA, AMR,115/83 :1-14.

Dzhuvinov, V. and H. Kutinkova (2003). Integrated plant protection of apple in Bulgaria. Sodininkyste-irDarzininkyste, 22(1): 55-61.

Feng, Jianguo; X.U.N. Tao; Vi. Yu; Ansheng Zhang; J.G. Feng; X. Tao; V. $\mathrm{Vu}$ and A.S. Zhang (2000). Study on pollution in apple orchards and better techniques for controlling diseases and pests in order to minimize social pollution. China Fruits, No. 2: 9-13. Hwang, E.S.; J.N. Cash and M.J. Zabik (2002). Degradation of mancozeb and ethylenethiourea in apples due to postharvest treatments and processing. $\boldsymbol{J}$. of Food Science, 67(9): 3295-3300. Masng, S. and A. Bielenin (2002). Influence of temperature on antisporulant activity of some fungicides used in control of apple powdery mildew.

Progress in Plant Protection, 42(2): 939941.

Mayer, D.F. and J.D. Lunden (1986). Toxicity of fungicides and an acaricide to honey bees (Hymenoptera: Apida) and their effects on bee foraging behaviour and pollen viability on blooming apples and pears. Environmental Entomology, 15: 1047-1049.

Moye, H.A.; M.H. Malagod; J.Yoh; G.L. Leibee; C.C. Ku; and P.G. Wilslockj (1987). Residues of avermectin $\mathrm{B}_{1} \mathrm{a}$ : Rotational crop and soils following soil treatment with $\left(\mathrm{C}_{14}\right)$ avermectin $\mathrm{B}_{1} \mathrm{a}$. Agric. Food Chem., 35: 859-864.

Nasr, I.N.; Nevein, S. Ahmed and M.M. AI-Maz (2003). Effect of boiling and some environmental factors on residues behaviour of penconazole fungicide on vine leaves. Annals Agric. Sci., Ain

Shams Univ., Cairo, 48(1): 365-372.

Nippon Soda Co. Ltd. (1984).

Analytical method for residues of triflumizole and its major metabolite in crops. RD-8450: 1-7. Nippon Soda Co. Ltd. Tokyo, Japan.

Nippon Soda Co. Ltd. (2004).

Maximum residue level (MRL) of triflumizole in registered crops in Japan: 1. Nippon Soda Co. Ltd. Tokyo, Japan February 2004.

Ong, K.C.; J.N. Cash; M.J. Zabik; M. Siddiq and A.L. Jones (1996). Chlorine and ozone washes for pesticide removal from apples and processed apple sauce. Food Chemistry, 55(2): 153-160. Pest Control Programme (2001). Published by Ministry of Agriculture and Land Reclamation. Dokki, Cairo, Egypt, pp. 124 and 244.

Pest Control Programme (2005).

Published by Ministry of Agriculture and Land Reclamation. Dokki, Cairo, Egypt, (under publication).

Podgornaya, M.E. (2003). Dynamics of decomposition of topas in orchard agrocoenosls. Zashchita-I-karantin Rastenii, No. 12:39-40.

Reuveni, M.; H. Cohen; T. Zahavi and A. Venezian (2000). Polar $\square$ apotant polyxin $\mathrm{B}$ compound for controlling 
Flusilazole and triflumizole residues in apple fruit

powdery mildews in apple and nectarine trees, and grapevines. Crop protection, 19(6): 393-399.

Sato, K. and S.I. Maki (1989). Fate and behaviour of the fungicide guazatine in the environment. J. of the Pesticide

Science, 14(3): 383-393.

Tomlin C.D.S. (2000). The Pesticide

Manual. 12 Ed.pp. 460 and 940.

Published by British Crop Protection

Council (BCPC), London, UK.

Ueno, E.; H. Oshima; I. Saito and H.

Matsumoto (2002). Multiresidue

analysis of nitrogen-containing and

sulphur-containing pesticides in

agricultural products using dual-column

GC-NPD/FPD. Shokuhin

Eiseigakuzasshi. $\boldsymbol{J}$. of the Food Hygienics Society of Japan, 43(2): 80-89.

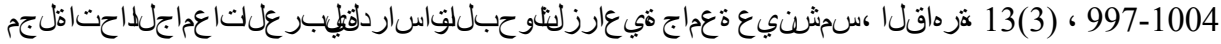
، 2005

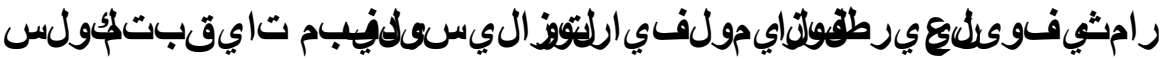

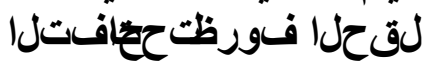

\section{]68[}

\section{1}

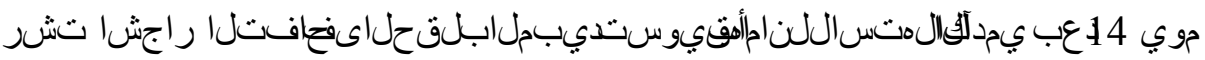

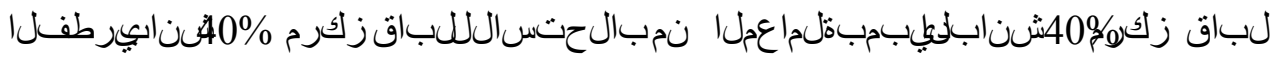

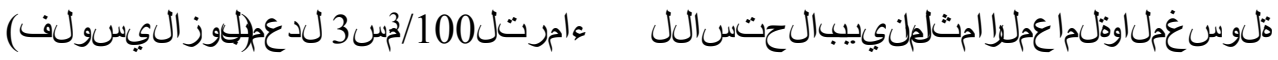

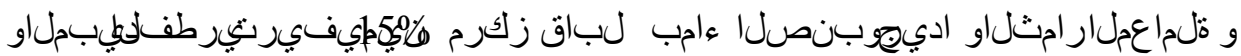

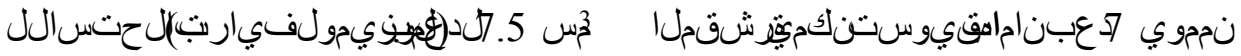

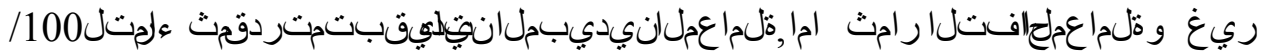

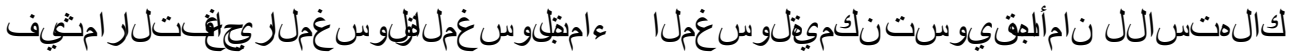

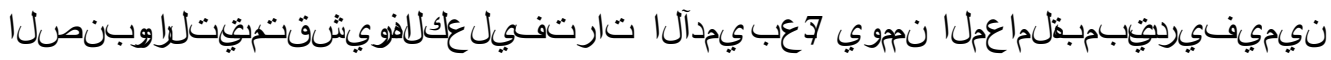

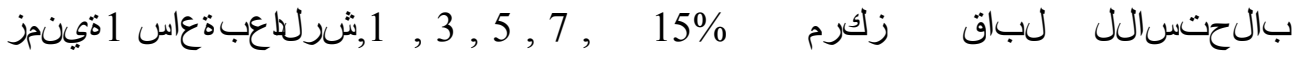

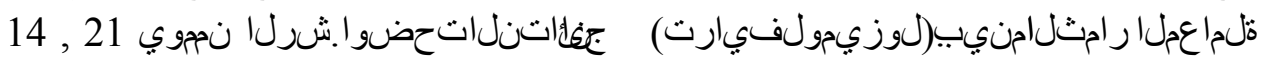

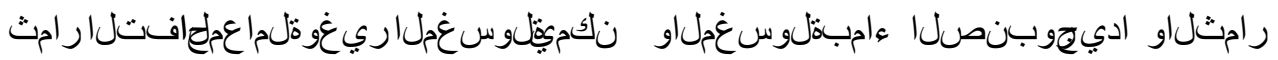


Arab Univ. J. Agric. Sci., Ain Shams Univ., Cairo, 13(3), 997 - 1004, 2005

ديبحل موي 1.14

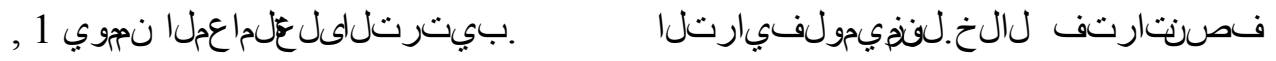

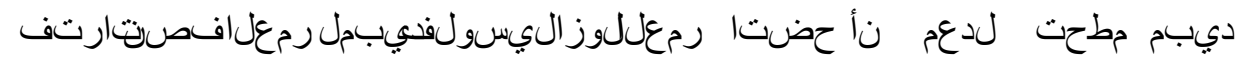

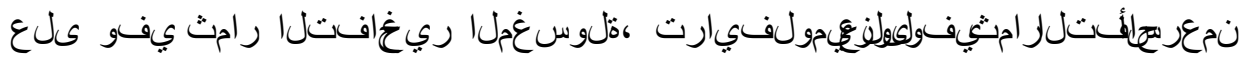

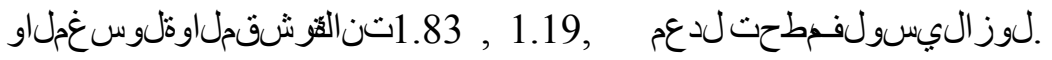

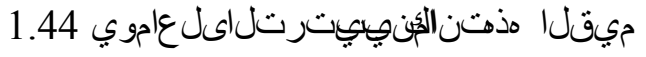

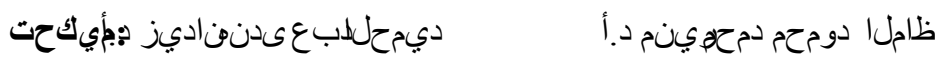

1- Central Agricultural Pesticides Laboratory, Agricultural Research Center, Dokki, Cairo, Egypt 